\title{
Health perception in menopausal women
}

International Journal of Women's Health

\author{
Mildren Del Sueldo $1,2, *$ \\ Nieves Martell-Claros ${ }^{3-5, *}$ \\ María Abad-Cardiel ${ }^{3-5}$ \\ Judith M Zilberman ${ }^{6-8}$ \\ Raul Marchegiani ${ }^{1,2}$ \\ Cristina Fernández-Pérez ${ }^{9}$ \\ 'Healthy heart program, \\ Municipalidad de Villa María, Córdoba, \\ Argentina; ${ }^{2}$ Cardiology Division \\ and Cardiovascular Prevention, \\ Specialty Clinic, Villa María, Córdoba, \\ Argentina; ${ }^{3}$ Hypertension Unit, \\ Internal Medicine Service, Hospital \\ Clínico San Carlos, Madrid, Spain; \\ ${ }^{4}$ School of Medicine, Complutense \\ University, Madrid, Spain; ${ }^{5}$ Research \\ Institute of the San Carlos Clinical \\ Hospital, Madrid, Spain; ${ }^{6}$ Physiology \\ Course at the School of Pharmacy \\ and Biochemistry, University of \\ Buenos Aires, IQUIMEFA-CONICET, \\ CABA, Argentina; ${ }^{7}$ Department \\ of Cardiovascular Prevention, \\ Hypertension Unit, Cardiovascular \\ Institute, Buenos Aires (ICBA), \\ CABA, Argentina; ${ }^{8} \mathrm{Cardiology}$ \\ Service, Hypertension Unit, Hospital \\ General de Agudos Dr. Cosme \\ Argerich, Buenos Aires, Argentina; \\ 'Unit of Epidemiology and Clinical \\ Methodology, Preventive Medicine \\ Service, Research Institute of the \\ San Carlos Clinical Hospital, UCM, \\ Madrid, Spain \\ *These authors contributed equally \\ to this work
}

\begin{abstract}
Aim: The aim of this study is to find whether the worsening of health perception was related to the menopausal (MNP) state or to its negative consequences on cardiometabolic risk factors (CMRF) and the presence of depression/anxiety.

Methods: In this study, 2,562 women, 1,357 (53\%) MNP and 1,205 (47\%) non-MNP, were analyzed. Blood pressure, heart rate, body mass index, waist circumference, and depression/ anxiety screening using the Hospital Depression/Anxiety Scale (HADS) were measured. We collected a blood sample in fasting state for glycemia, total cholesterol, high-density lipoprotein cholesterol, low-density lipoprotein cholesterol and triglycerides. Logistic regression models were fitted with a backward method from the potentially confusing variables of the menopause study groups.
\end{abstract}

Results: Age 49.4 ( \pm 15.9 ) years; $10.1 \%$ belonged to semi-rural population; $87.5 \%$ had children. Regarding the educational level, $22.1 \%$ had $<5$ years of education, $31.3 \%$ had between 6 and 7 years, 33.4\% had between 8 and 12 years, and 13.2\% had $>12$ years of education. The prevalence of CMRF was significantly higher in MNP women, except for smoking. We did not find any differences in the prevalence of depression or anxiety between MNP and nonMNP women. Health was perceived as worse among MNP women $(P<0.05)$ and patients over 45 years of age than patients younger than 45 years. We found a relationship between the negative health perception with metabolic syndrome, depression, and anxiety, having children, smoking, residing in rural area, and low educational level; nevertheless, it is not correlative with MNP status.

Conclusion: Perceived health should be viewed as a multifaceted condition related to social circumstances, and various symptoms in women, including menopause symptoms, but not with MNP state itself.

Keywords: menopause, health perception, depression, anxiety, metabolic syndrome

\section{Introduction}

Cardiovascular diseases are the leading cause of death in the world. More than half (54\%) of the 56.4 million deaths occurred in 2015 were due to ten causes. Ischemic heart disease and stroke were the biggest culprits, with up to 15 million deaths attributable to both of them in that year alone. Diabetes caused 1.6 million deaths. These diseases have been the main causes of global mortality for the past 15 years. ${ }^{1}$

To optimize the preventive measures of cardiovascular diseases, it is essential that people have an adequate perception of cardiovascular risk factors, given that they lack specific symptoms, although they may present mild generic symptoms, with a loss of well-being that the patient should be able to perceive. ${ }^{2-6}$

Perceived health status is one of the majorly used indicators when evaluating the real health of the population providing the first sight of the individual's life satisfaction. It is one of the most consolidated and frequently asked indicators in health surveys. Although health perception measurement is subjective, there is a close relationship
Correspondence: Nieves Martell-Claros Unidad de Hipertensión, Servicio de Medicina Interna, Hospital Clínico San Carlos, C/Martin Lagos s/n, Madrid, Spain Email nieves.martell@salud.madrid.org 
between health assessment and other consequences of such assessment acceptance. Generally, it has been shown that people who perceive their health as poor see their mortality increased due to cardiovascular diseases, cancer, and other diseases. $^{2-6}$

The relationship between sex and health perception is close. Women tend to have a worse perception of their own health than men at all ages, especially when they are over 50 years of age. This could be related to the onset of menopause, which, in turn, leads to an increase in cardiovascular risk. However, it is a fact that women universally have a higher life expectancy than men.

The excess of minor physical morbidity reported among women compared with men has been widely confirmed in large representative community population samples in North America and Europe. However, men have poorer health in chronic conditions related to the leading causes of death. ${ }^{7}$ Hospitalization rates are higher in men over 50 years of age, and hospital stays are longer ${ }^{8}$ for men compared with women.

In the face of this controversy, this study tries to answer whether the worsening of health perception was related to the menopausal (MNP) state or to the negative consequences on cardiometabolic risk factors and/or depression/anxiety presence.

\section{Subjects}

In this study, women $\geq 21$ years of age who participated in the "Healthy Heart" Cardiovascular Disease Prevention Program were included. This study was designed to identify the prevalence in the population of cardiovascular diseases and risk factors. Exclusion criteria were as follows: $<21$ years, pregnant, or disability and/or inability to sign the informed consent or complete the studies required by the protocol.

\section{Sample calculation}

The present study is an epidemiological, cross-sectional, exploratory, and a posteriori inferential one. The field work was carried out in the towns of Villa María (Córdoba) and Rancúl (La Pampa), Argentina.

The sample size was estimated considering a proportion of poor health perception of $50 \%$ (proportion in which the largest sample size is required), with an estimation error of $2 \%$ and an estimated loss ratio of $10 \%$. The sample size needed was 2,415 women.

The sampling was multistage, stratified by sex and age, based on previous records of the population. The work was carried out in the Primary Health Care Centers of both locations.
A probabilistic sample of the population of the city was extracted, which means that the selection was done in such a way that every subject of the population (and, therefore, of every subject within each group of expected age) will have a nonzero probability and known in advance to be chosen. Specifically, a multistage stratified sampling was applied.

The sampling was multistage, considering the nominal population in charge of each Primary Health Care Center (PHC) of the mentioned municipalities (Villa María y Rancúl), with representation of all the strata of age contemplated in the design.

The final selected sample included 2,562 women, corresponding to 2,294 women in the city of Villa María and 268 in the town of Rancúl (Figure 1).

\section{Methods}

\section{Blood pressure and heart rate}

Three records of blood pressure and heart rate were obtained, with an interval of 2 minutes between each measurement, considering the average of the last two as a valid measure. The blood pressure was taken in the sitting position with the arm supported at rest at heart level.

An electronic digital sphygmomanometer (OMRON model HEM 7200-E) validated by the British Hypertension Society and the European Hypertension Society was used.

\section{Weight and height}

Weight (in kilograms) and height (in centimeters) were measured using a properly calibrated weighing scale with altimeter. The weight and height measurements were taken with the subjects not wearing shoes and wearing light clothing as a measurement parameter.

\section{Waist circumference}

The circumference of the waist was measured at a midpoint between the rib flange and the iliac crest with the participant standing, with the torso exposed, both arms on the sides of the body and in unintended exhalation.

\section{Blood determinations}

Blood samples were collected from the participants after 12-hour fasting. Glycemia, total cholesterol, high-density lipoprotein (HDL) cholesterol, low-density lipoprotein (LDL) cholesterol and triglycerides were determined.

\section{Hypertension}

Hypertension was defined as systolic blood pressure $(\mathrm{SBP}) \geq 140 \mathrm{mmHg}$ and/or diastolic blood pressure 


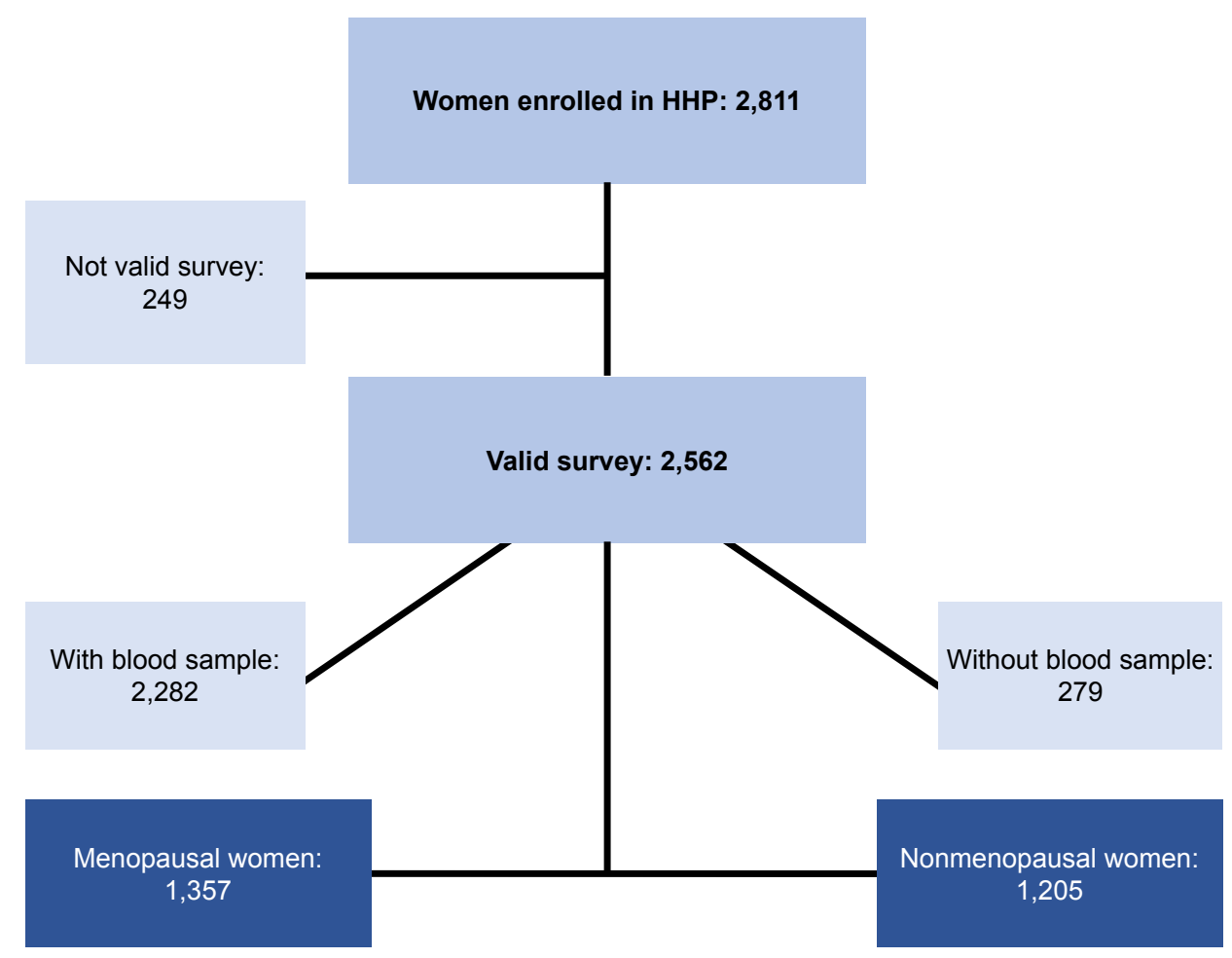

Figure I Flow chart of women enrolled in the study.

(DBP) $\geq 90 \mathrm{mmHg}$ (5) and/or the current use of antihypertensive drugs. ${ }^{9}$

\section{Smoking}

People who, at the time of the survey, reported having smoked daily or occasionally were considered smokers; those who had never smoked and those who had not smoked for more than 6 months were considered nonsmokers.

\section{Overweight - obesity}

Body mass index (BMI) was calculated using the Quetelet Index (weight/height squared). A BMI between 20 and 24.9 $\mathrm{kg} / \mathrm{m}^{2}$ defined as normal, $25-29.9 \mathrm{~kg} / \mathrm{m}^{2}$ as overweight, and $\geq 30 \mathrm{~kg} / \mathrm{m}^{2}$ obesity. Abdominal obesity was considered when waist circumference was $\geq 88 \mathrm{~cm} .{ }^{10}$

\section{Diabetes}

Abnormal fasting plasma glucose (FPG) was considered when blood glucose was $\geq 100 \mathrm{mg} / \mathrm{dL}$ and diabetes when fasting blood glucose was $\geq 126 \mathrm{mg} / \mathrm{dL}$ and/or current use of hypoglycemic agents and/or insulin. ${ }^{11}$

\section{Dyslipidemia}

Dyslipidemia was defined as such when the analysis performed yielded one or more of the following results: total cholesterol $\geq 200 \mathrm{mg} / \mathrm{dL}$ and/or HDL cholesterol $\leq 50 \mathrm{mg} / \mathrm{dL}$, and/or triglycerides $\geq 150 \mathrm{mg} / \mathrm{dL}$ or current treatment with drugs lipid-lowering agents. ${ }^{12}$

\section{Metabolic syndrome}

ATP III criteria ${ }^{10}$ was used, which defines the metabolic syndrome as the presence of three of the following five traits: 1) abdominal obesity, defined as a waist circumference in women $\geq 88 \mathrm{~cm} ; 2$ ) serum triglycerides $\geq 150 \mathrm{mg} / \mathrm{dL}$ or drug treatment for elevated triglycerides; 3 ) serum HDL cholesterol $<50 \mathrm{mg} / \mathrm{dL}$ in women or drug treatment for low HDL cholesterol; 4) blood pressure $\geq 130 / 85 \mathrm{mmHg}$ or drug treatment for elevated blood pressure; and 5) FPG $\geq 100 \mathrm{mg} / \mathrm{dL}$ or drug treatment for elevated blood glucose.

\section{Anxiety/depression}

Anxiety/depression evaluated with HADS, as an approximation to the state of mind. It assessed depressive and anxious symptoms, rating the severity of the symptom. HADS is a self-applied questionnaire with 14 items. Two subscales of 7 items each, on a Likert scale of 0-3. HAD anxiety: odd items, and HAD Depression: even elements, with a score range on each subscale of $0-21$. Higher score, greater anxiety and depression. For both subscales scores, $>11$ would indicate "case." 13 
The population educational level was stratified into four: 1) incomplete primary education equals $<5$ years of education, 2) complete primary education equals 6-7 years of education, 3) incomplete/complete secondary education equals $8-12$ years of education and 4) tertiary university/ incomplete/complete to $>12$ years of education.

Menopause was considered when the woman presented amenorrhea for 1 year or more. ${ }^{14}$

\section{Statistical analysis}

The descriptive statistical analysis was performed from the summary measurements and the comparisons were made applying bivariate analyses with parametric or nonparametric tests, as appropriate. We work with 95\% CI.

A descriptive analysis of mean and SD for quantitative variables and frequency for qualitative variables was performed. For the comparison of qualitative variables, the chi-squared test was used; and for the quantitative variables, the Student's $t$-test was used before studying the homogeneity of variables. Logistic regression models were fitted with a backward method from the potentially confusing variables of the menopause study groups. The ORs and their 95\% CI are presented in all tests. All data analyses were performed using the SPSS Version 20 package. All $P$-values were two-tailed, and the cutoff of significant level was defined as $P<0.05$. The work was approved by the ethical committee of the University Hospital Favaloro Foundation.

\section{Results}

In this study, 2,811 women were recruited, of which 249 were withdrawn from the study due to lack of data in the survey; the final valid population was 2,562 women (Figure 1). The average age was 49.4 ( \pm 15.9$) ; 10.4 \%$ belonged to semirural population and the rest to urban population; $87.5 \%$ of the population had one child or more than one; $40.9 \%$ of the population worked outside their home. Regarding the educational level, $22.1 \%$ of the population had $<5$ years of education, $31.3 \%$ had between 6 and 7 years, $33.4 \%$ had between 8 and 12 years and $13.2 \%$ had over 12 years of education (Table 1).

In our study, 1,357 (53\%) women were MNP and 1,205 (47\%) were non-MNP. The 249 excluded women presented similar characteristics to those who remained in the study.

Blood sample for analytical was obtained from 2,283 women (89\%). The characteristics of MNP and non-MNP women are shown in Table 2 . There are statistically significant differences $(P<0.001)$ in age, SBP and DBP, heart rate, lipid profile, glycemia, and waist circumference.
Table I Sociodemographic characteristics of the women population with respect to education

\begin{tabular}{|l|l|}
\hline $\mathrm{N}$ & 2,562 \\
\hline Age (years), mean (SD) & $49.4(15.9)$ \\
\hline Semi-rural population & $10.4 \%$ \\
\hline Urban population & $89.5 \%$ \\
\hline Children (yes) & $87.5 \%$ \\
\hline Work outside home & $40.9 \%$ \\
\hline Educational level & $22.1 \%$ \\
\hline$<5$ years & $31.3 \%$ \\
\hline $6-7$ years & $33.4 \%$ \\
\hline $8-12$ years & $13.2 \%$ \\
\hline$>12$ years & \\
\hline
\end{tabular}

Notes: The educational level of the population was stratified into four: I) incomplete primary education equals $<5$ years of education, 2) complete primary education equals 6-7 years of education, 3) incomplete/complete secondary education equals 8-12 years of education, and 4) tertiary university/incomplete/complete to $>12$ years of education. The $64.7 \%$ of women have completed primary and/or secondary education.

BMI mean differs significantly between both groups. However, no differences were found in the overweight range. More women were found within normal weight among non-MNP women $(P<0.001)$, and a higher

Table 2 Baseline characteristics of the studied population $\mathrm{N}=2,562$

\begin{tabular}{|c|c|c|c|}
\hline Variables & $\begin{array}{l}\text { Menopausal } \\
\text { women }\end{array}$ & $\begin{array}{l}\text { Nonmenopausal } \\
\text { women }\end{array}$ & $P$-value \\
\hline $\mathbf{N}$ & 1,357 & 1,205 & \\
\hline Age (years) & $61.6 \pm 9.2$ & $35.7 \pm 9.2$ & $<0.001$ \\
\hline SBP $(\mathrm{mmHg})$ & $139 \pm 23.2$ & $121 \pm 18.1$ & $<0.001$ \\
\hline $\mathrm{DBP}(\mathrm{mmHg})$ & $79 \pm 12.5$ & $73 \pm 12$ & $<0.001$ \\
\hline $\mathrm{HR}(\mathrm{b} / \mathrm{m})$ & $74.2 \pm I I . I$ & $78.4 \pm 10.8$ & $<0.001$ \\
\hline Triglycerides (mg/dL) & $143 \pm 6.9$ & $119 \pm 6.9$ & $<0.001$ \\
\hline $\begin{array}{l}\text { Total cholesterol } \\
(\mathrm{mg} / \mathrm{dL})\end{array}$ & $2|5 \pm 4|$ & $185 \pm 49$ & $<0.001$ \\
\hline HDLc (mg/dL) & $55 \pm 12$ & $52 \pm 12$ & $<0.001$ \\
\hline LDLc (mg/dL) & $|3| \pm 34$ & $109 \pm 30$ & $<0.001$ \\
\hline Glycemia (mg/dL) & $89.8 \pm 31$ & $82.3 \pm 27$ & $<0.001$ \\
\hline WC $(\mathrm{cm})$ & $96.9 \pm 13$ & $91.1 \pm 15$ & $<0.001$ \\
\hline BMI & $29.8 \pm 6.1$ & $28.2 \pm 6.7$ & $<0.001$ \\
\hline$<25, \mathrm{n}(\%)$ & $218(8.6 \%)$ & 404 (I5.9\%) & $<0.001$ \\
\hline 25-29.9, n (\%) & 494 (19.5\%) & 368 (I4.5\%) & ns \\
\hline$\geq 30, \mathrm{n}(\%)$ & $632(24.9 \%)$ & $420(16.6 \%)$ & $<0.001$ \\
\hline
\end{tabular}

Note: There are statistically significant differences in age, SBP and DBP, heart rate, lipid profile, glycemia and waist circumference between menopausal and nonmenopausal women.

Abbreviations: BMI, body mass index; HDLc, high-density lipoprotein cholesterol; HR (b/m), heart rate/beats per minute; LDLc, low-density lipoprotein cholesterol; WC, waist circumference. 
Table 3 Risk factor and metabolic syndrome in menopausal and nonmenopausal women

\begin{tabular}{|c|c|c|c|c|c|}
\hline \multirow[t]{3}{*}{ Variables } & \multirow{2}{*}{\multicolumn{2}{|c|}{$\begin{array}{l}\text { Menopausal women } \\
n=1,357\end{array}$}} & \multirow{2}{*}{\multicolumn{2}{|c|}{$\begin{array}{l}\text { Nonmenopausal women } \\
n=I, 205\end{array}$}} & \multirow[t]{3}{*}{$P$-value } \\
\hline & & & & & \\
\hline & $\mathbf{n}$ & $\%(95 \% \mathrm{Cl})$ & $\mathbf{n}$ & $\%(95 \% \mathrm{Cl})$ & \\
\hline High blood pressure & 765 & $56.4(53.7-59.0)$ & 222 & $18.4(16.3-20.7)$ & $<0.001$ \\
\hline Hypertriglyceridemia & 505 & $37.2(4.7-39.8)$ & 261 & $21.7(19.4-24.1)$ & $<0.001$ \\
\hline Hypercholesterolemia & 778 & $57.3(54.7-59.9)$ & 332 & $31.8(25.1-30.2)$ & $<0.001$ \\
\hline LDLc (mg/dL) & 622 & $50.4(43.2-48.5)$ & 263 & $25.2(19.6-24.3)$ & $<0.001$ \\
\hline HDLc (mg/dL) & 441 & $32.5(30.1-35.0)$ & 443 & $36.8(34.1-39.5)$ & $<0.001$ \\
\hline Metabolic syndrome (yes) & 558 & $41.1(38.5-43.8)$ & 245 & $20.3(\mid 8.2-22.7)$ & $<0.001$ \\
\hline Smoking & 288 & $21.2(19.1-23.5)$ & 400 & $33.2(30.6-35.9)$ & $<0.001$ \\
\hline
\end{tabular}

Notes: The prevalence of cardiovascular risk factors was significantly higher in menopausal women, except for smoking that was higher in nonmenopausal women. High blood pressure, blood pressure $\geq 140 / 90 \mathrm{mmHg}$ or drug treatment for elevated blood pressure; Hypertriglyceridemia triglycerides, $\geq 150$ mg/dL or drug treatment for elevated triglycerides. Hypercholesterolemia, total cholesterol $\geq 200 \mathrm{mg} / \mathrm{dL}$ or drug treatment for elevated total cholesterol. Metabolic syndrome, defined by ATP III presence of any three of the following five traits: I) abdominal obesity, defined as a waist circumference in women $\geq 88 \mathrm{~cm}, 2)$ Serum triglycerides $\geq I 50 \mathrm{mg} / \mathrm{dL}$ or drug treatment for elevated triglycerides, 3) Serum HDLc $<50 \mathrm{mg} / \mathrm{dL}$ in women or drug treatment for low HDLc, 4) Blood pressure $\geq 130 / 85 \mathrm{mmHg}$ or drug treatment for elevated blood pressure, 5) Fasting plasma glucose (FPG) $\geq 100 \mathrm{mg} / \mathrm{dL}$ or drug treatment for elevated blood glucose.

Abbreviations: HDLc, high-density lipoprotein cholesterol; $95 \% \mathrm{Cl}, 95 \%$ confidence interval; LDLc, low-density lipoprotein cholesterol.

prevalence of obesity among MNP women $(P<0.001)$ was detected.

The prevalence of cardiovascular risk factors was significantly higher in MNP women, except for smoking that was higher in non-MNP women. All differences were statistically significant (Table 3).

As variables can influence the perception of health, the anxiety and depression tests were performed using the HADS scale, considering a pathological score $\geq 11$ for both. We did not find any differences in the prevalence of depression (12.2 vs $15.5, P=\mathrm{ns})$ or anxiety ( 20.7 vs $27.3, P=\mathrm{ns})$ between MNP and non-MNP women.

Health was perceived as worse among MNP women $(P<0.05)$. Patients under 45 years of age also had a better perception of health than older patients (Table 4). For the subsequent analysis of health perception, we divided the samples into three categories: good, very good, and excellent into a single category (good or more) and maintaining the regular and bad categories.
We found a relationship between the negative perception of health with metabolic syndrome, depression, and anxiety, having children, smoking, residing in rural area, and low educational level; nevertheless, it does not correlate with MNP status (Table 5).

\section{Discussion}

The main finding of the present study was that self-reported poor health was strongly associated with metabolic syndrome, depression and anxiety, having children, smoking, residing in rural or semi-rural areas and low educational level; nevertheless, it does not correlate with menopause.

The advantages of this study were the well-defined study population, as well as the response rate of almost $100 \%$. Other strength was the focus on a large random sample of the Argentinean population.

In this study, it was possible to simultaneously control variables such as age, self-reported health status, educational level, etc. Population was large enough to analyze data

Table 4 Perception of health by age groups and menopausal status

\begin{tabular}{|l|l|l|l|l|l|l|}
\hline & $\begin{array}{l}\text { Total } \\
\text { population (\%) }\end{array}$ & $\mathbf{4 5}$ years (\%) & $\mathbf{4 5 - 6 0}$ years (\%) & $>\mathbf{6 0}$ years (\%) & MNP (\%) & Non-MNP (\%) \\
\hline Excellent & 2.8 & 4.0 & 1.6 & 2.6 & 2.1 & 3.5 \\
\hline Very good & 11.3 & 14.5 & 8.5 & 10.2 & 9 & 43.9 \\
\hline Good & 41.9 & 41.9 & 41.1 & 42.7 & 42.1 & 41.6 \\
\hline Regular & 36.6 & 33.5 & 39.3 & 37.4 & 37.9 & 35.1 \\
\hline Bad & 5.4 & 4.8 & 6.9 & 4.5 & 6.1 & 4.6 \\
\hline No reply & 2.1 & 1.3 & 2.6 & 2.6 & 2.7 & 1.4 \\
\hline Total (N) & 2,548 & 957 & 858 & 733 & 1,351 & 1198.0 \\
\hline
\end{tabular}

Note: Health is perceived worse in MNP women, and patients under 45 years showed better health perception than older patients.

Abbreviation: MNP, menopausal. 
Table 5 Variables that negatively influence the perception of health

\begin{tabular}{|l|l|l|l|}
\hline & OR & $\mathbf{9 5 \%} \mathbf{C I}$ & P-value \\
\hline Metabolic syndrome & 1.501 & $1.116-2.019$ & 0.007 \\
\hline Depression & 1.097 & $1.058-1.138$ & $<0.00 \mathrm{I}$ \\
\hline Anxiety & 1.096 & $1.077-1.036$ & $<0.00 \mathrm{I}$ \\
\hline Have children & 1.572 & $1.148-2.153$ & 0.005 \\
\hline Smoking & 1.297 & $1.074-1.566$ & 0.007 \\
\hline Place of residence (rural) & 1.930 & $1.015-3.668$ & $<0.00 \mathrm{I}$ \\
\hline Years of education & 0.630 & $0.433-0.920$ & $<0.00 \mathrm{I}$ \\
\hline
\end{tabular}

Notes: Model that explains the poor perceived health. The negative perception of health is related with metabolic syndrome, depression and anxiety, having children, smoking, residing in rural area and low educational level; nevertheless, it does not correlate with menopausal status.

separately in relation to non-MNP and MNP women and two age groups.

These types of surveys have a long tradition; therefore, there is a considerable amount of experience associated with it. The questions were well validated and have been consistent over the years, according to the HAD Scale, ${ }^{13}$ and they have a high reliability.

Health surveys suggest that women generally perceive their health worse than men; that health professionals tend to overestimate our state of health; and that aging increases negative perception of their health (phenomenon of underestimation of health). ${ }^{13}$ Depression is an important mental health problem that impairs personal functioning and affects one in four women in their lifetime. ${ }^{15,16}$ It has been suggested that estrogen deficiency may increase the susceptibility to depression. ${ }^{17}$

Results on this study indicate that health was perceived as worse in MNP women $(P<0.05)$ compared with non-MNP women. Patients younger than 45 years had a better perception of health than older patients.

We found a relationship between the negative perception of health and metabolic syndrome, depression, and anxiety, having children, smoking, residing in rural areas and low educational level; nevertheless, it does not correlate with menopause.

Results on this study contrast with those of Yen et al. ${ }^{18}$ A total of 672 Aboriginal women aged between 40 and 60 years (mean age: 49.43土5.33) were studied, of which 182 (38.3\%) were classified as the depressive group. Conclusions drawn on that study were that perimenopausal states were associated with depression and women with a perimenopausal state had a higher prevalence of depression than those with a premenopausal state. Somatic symptoms were associated with depression for pre, peri, and postmenopausal states.
What the authors related to depression is not exactly the MNP state, but the presence of vasomotor somatic symptoms.

In this study, negative perception of health associated with metabolic syndromes was found, which is in agreement with the previous findings of Burger et al, establishing that menopause is accompanied by adverse changes, including altered serum lipid profiles, hormonal changes, and neuroendocrine and immune system changes. ${ }^{19-21}$

Hypertension was related to poor perceived health in women but not in men. Likewise, women with poor selfperceived health were much more likely to be obese than women with good health. ${ }^{2}$

The study showed a negative perception of health related to depression, anxiety and residing in rural areas; in accordance with the results of Yen et $\mathrm{al}^{18}$ that related vasomotor symptoms with depression. The association between depression and perimenopausal status demonstrates that depression is also an important mental health issue for women going through MNP transition in rural areas. Physiological MNP symptoms were the factors most associated with depression, under control of psychosocial factors mentioned above in the present study. These results may also suggest a possible biological link between depression and MNP symptoms.

Results in this study showed that smoking has an inverse correlation with the perception of health, in concordance with other studies which confirm that both smoking men and women who had no regular physical activity perceived their health as worse than nonsmokers and physically active persons. Both men and women with poor self-perceived health were about twice as likely to be smokers. ${ }^{2}$

Lower educational levels were related to the ability to estimate risk and, thus, intelligence and other cognitive functions may further explain such ability. ${ }^{22}$ Individuals who had a university/college education were less likely to perceive their health as poor. ${ }^{2}$ On the other hand, a low educational level ( $<9$ years) was also associated with increased mortality risks for men and women. ${ }^{23}$

Alcohol consumption was also related to ability to estimate risk, but this relation is not easy to understand and needs further confirmation. ${ }^{22}$

In this study, it was found that having children has an inverse correlation with the perception of health. This is probably related to the findings of Lui Filho ${ }^{24}$ who found that the number of births is associated with more severe symptoms of menopause in Brazilian women.

Results in this study should be interpreted in the light of three limitations. First, the stigmatization of mental health disorders might make women unwilling to admit their 
depression in the interviewing study. Second, the crosssectional research design of the present study could not confirm causal correlations between MNP symptoms and depression. Third, women with MNP symptoms were not separated from the rest. However, given the large sample selected, this point could have been diluted.

\section{Conclusions}

Perceived health should be viewed as a multifaceted condition related to social circumstances, and various symptoms in women, including MNP symptoms, but not with menopause itself.

\section{Acknowledgment}

Fundación CERTUS Villa María. Córdoba. Argentina. The abstract of this paper was presented at the 28th European Meeting on Hypertension and vascular Protection as a poster presentation. The authors report no conflicts of interest in this work.

\section{Disclosure}

The authors report no conflicts of interest in this work.

\section{References}

1. WHO $\mid$ World Health Organization [Internet]. WHO. [cited 2017 Jul 15]. Available from: http://www.who.int/mediacentre/factsheets/fs310/\%20 (Accessed\%2014\%20Jun\%202017\%20)

2. Welin C, Wilhelmsen L, Welin L, Johansson S, Rosengren A. Perceived health in 50-year-old women and men and the correlation with risk factors, diseases, and symptoms. Gend Med. 2011;8(2):139-149.

3. Kaplan GA, Camacho T. Perceived health and mortality: a nine-year follow-up of the human population laboratory cohort. Am J Epidemiol. 1983;117(3):292-304.

4. Rakowski W, Mor V, Hiris J. The association of self-rated health with two-year mortality in a sample of well elderly. J Aging Health. 1991;3(4):527-545.

5. Sundquist J, Johansson SE. Self reported poor health and low educational level predictors for mortality: a population based follow up study of 39,156 people in Sweden. J Epidemiol Community Health. 1997;51(1):35-40.

6. Heistaro S, Jousilahti P, Lahelma E, Vartiainen E, Puska P. Self rated health and mortality: a long term prospective study in eastern Finland. J Epidemiol Community Health. 2001;55(4):227-232.

7. Ladwig KH, Scheuermann W. Gender differences in the decline of mortality rates of acute myocardial infarction in West Germany. Eur Heart J. 1997;18(4):582-587.
8. Verbrugge LM. Work satisfaction and physical health. J Community Health. 1982;7(4):262-283.

9. Mancia G, de Backer G, Dominiczak A. 2007 ESH-ESC Practice Guidelines for the Management of Arterial Hypertension: ESH-ESC Task Force on the Management of Arterial Hypertension. J Hypertens. 2007;25(9):1751-1762.

10. Grundy SM, Brewer HB, Cleeman JI, et al. Definition of metabolic syndrome: Report of the National Heart, Lung, and Blood Institute/ American Heart Association conference on scientific issues related to definition. Circulation. 2004;109(3):433-438.

11. Bloomgarden Z. American Diabetes Association Annual Meeting, 1997: obesity, diabetes prevention, and type 1 diabetes. Diabetes Care. 1997;20(12):1913-1917.

12. National Cholesterol Education Program, National Heart, Lung, and Blood Institute, National Institutes of Health. Detection, Evaluation, and Treatment of High Blood Cholesterol in Adults (Adult Treatment Panel III) Final Report; 2012.

13. Zigmond AS, Snaith RP. The hospital anxiety and depression scale Acta Psychiatr Scand. 1983;67(6):361-370.

14. Soules MR, Sherman S, Parrott E, et al. Executive summary: Stages of Reproductive Aging Workshop (STRAW). Climacteric. 2001;4(4): 267-272.

15. Kessler RC, Mcgonagle KA, Zhao S, et al. Lifetime and 12-month prevalence of DSM-III-R psychiatric disorders in the United States. Results from the National Comorbidity Survey. Arch Gen Psychiatry. 1994;51(1):8-19.

16. Zilberman JM, Cerezo GH, del Sueldo M, Fernandez-Pérez C, MartellClaros N, Vicario A. Association between hypertension, menopause, and cognition in women. J Clin Hypertens. 2015;17(12):970-976.

17. Hunter M, Rendall M. Bio-psycho-socio-cultural perspectives on menopause. Best Pract Res Clin Obstet Gynaecol. 2007;21(2):261-274.

18. Yen JY, Yang MS, Wang MH, et al. The associations between menopausal syndrome and depression during pre-, peri-, and postmenopausal period among Taiwanese female aborigines. Psychiatry Clin Neurosci. 2009;63(5):678-684.

19. Burger HG, Hale GE, Robertson DM, Dennerstein L. A review of hormonal changes during the menopausal transition: focus on findings from the Melbourne Women's Midlife Health Project. Hum Reprod Update. 2007;13(6):559-565.

20. Gameiro CM, Romão F, Castelo-Branco C. Menopause and aging: changes in the immune system - a review. Maturitas. 2010;67(4): 316-320.

21. Zilberman JM. Menopausia: hipertension arterial y enfermedad vascular. Hipertensión y Riesgo Vascular. 2018;35(2):77-83.

22. Frijling BD, Lobo CM, Keus IM, et al. Perceptions of cardiovascular risk among patients with hypertension or diabetes. Patient Educ Couns. 2004;52(1):47-53.

23. Sundquist J, Johansson SE. Self reported poor health and low educational level predictors for mortality: a population based follow up study of 39156 people in Sweden. J Epidemiol Commun Health. 1997;51:35-40.

24. Lui Filho JF, Baccaro LF, Fernandes T, Conde DM, Costa-Paiva L, Pinto Neto AM. Factors associated with menopausal symptoms in women from a metropolitan region in Southeastern Brazil: a population-based household survey. Rev Bras Ginecol Obstet. 2015;37(4):152-158.
International Journal of Women's Health

\section{Publish your work in this journal}

The International Journal of Women's Health is an international, peerreviewed open-access journal publishing original research, reports, editorials, reviews and commentaries on all aspects of women's healthcare including gynecology, obstetrics, and breast cancer. The manuscript management system is completely online and includes

\section{Dovepress}

a very quick and fair peer-review system, which is all easy to use. Visit http://www.dovepress.com/testimonials.php to read real quotes from published authors. 